\title{
Potential impact of increased heat tolerance of grain formation on maize yield under future warming
}

\author{
Y. Zhang ${ }^{a}$ and $\underline{\text { Y.X. Zhao }}{ }^{\text {a, b }}$ \\ ${ }^{a}$ Chinese Academy of Meteorological Sciences, Beijing, P. R. China \\ ${ }^{b}$ Shanghai Institute of Meteorological Sciences, Shanghai 200030, China. \\ Email:zyx@cams.cma.gov.cn
}

\begin{abstract}
Variety has been a dominant factor in crop production to achieve high yield. Efforts to identify suitable crop varieties to increase yield under future climate conditions remains essential for sustainable agriculture development and food security.

Previous studies have evaluated the impact of varietal changes on crop productivity under global warming, mostly in terms of varietal improvement that changed growing duration, growth characteristics and disease resistance. Potential impact of varietal improvement to increase the tolerance of grain formation to extreme temperatures has been rarely studied, particularly in the North China Plain (NCP).

The objective of this study is to assess the likely impacts of future climate change scenarios on maize productivity in North China Plain (NCP), and evaluate the potential impact of using 'new' varieties with increased tolerance of grain number formation to high temperatures in response to climate warming.

The 'new' maize variety, derived from existing variety Xundan29 in the APSIM model package, has a higher tolerance of pollen viability to high temperature. That is its grain number development has a higher maximum temperature threshold of $40^{\circ} \mathrm{C}$ as compared to Xundan $29\left(38^{\circ} \mathrm{C}\right)$.

The process-based crop model APSIM, coupled with outputs of a regional climate model RegCM4, was used to simulate the impact of climate warming on maize yield in the periods of 2020-2045 based on RCP4.5 and RCP8.5 at Yuanyang, Yongnian and Shijiazhuang in the NCP.

Results show that the reduction in maize yield caused by climate warming (without considering the contribution of variety adaptation) increased from northern to southern sites, by $12 \%$ on average, taking 1980-2005 as the baseline period. Introduction of a variety with increased tolerance of grain number formation to high temperature could be one of the effective adaptation strategies to offset the negative impact of climate change. It could lead to an average yield increase of $1-9 \%$ as compared to no adaptation, depending on sites and climate scenarios.
\end{abstract}

Keywords: $\quad$ Climate change, adaptation, maize yield, heat tolerant variety 


\section{INTRODUCTION}

Variety is the most important factors in crop production to obtain high yield. Adopting modern variety has dramatically increased crop yields. For example, Yu et al. (2012) estimated that variety improvement contributed 39\% increase in rice yield in China from 1980 to 2009. Liu et al. (2013) showed that about $13 \%$ to $38 \%$ of maize yield increase could be attributed to variety improvement in Northeast China from 1981 to 2007. Variety change is an effective adaptation option to compensate the adverse climate change impacts in many regions (Tao et al., 2013; Zhang et al., 2013), and will remain as a key option for sustainable agriculture development and food security in future climate.

Maize grain yield is closely associated with the number of grains (Andrade et al., 1999; Tollenaar et al., 2000). Grain number is highly variable and very sensitive to environmental stresses such as high temperature in the period centered at flowering (Edreira et al., 2011; Rezaei et al. 2014). For example, heat stress reduces the number of flowers/plant, pollen tube development, limits pollen release and diminishes both pollen viability and flower fertility, all leading to the decline in grain number (Cárcova and Otegui 2001; Prasad et al., 2006). Furthermore, heat stress is likely to become more frequent with climate warming and would have more serious consequences for grain production (Lobell et al. 2013; Teixeira et al., 2013; Deryng et al. 2014). Varietal changes with improved heat tolerance, expressing with a higher tolerance for the cardinal temperatures, have proven to be a successful adaptation to cope with heat stress (Tao and Zhang, 2010; Tachie-Obeng et al., 2013). Relatively few studies have focused on related genotypic adaptation through improved tolerance of pollen viability, e.g. formation of grain number, to high temperature.

Maize is one of the main grain crops in China, and the North China Plain (NCP) is the largest summer maize production area in China. The growing season for maize in NCP experiences the hot summer. Heat stress, particularly during the crop reproductive period, could result in dramatic yield reductions in NCP (Tao et al., 2010, Zhao et al., 2012). However little is known about the potential impact of using 'new' varieties with increased tolerance of grain number formation to high temperatures in response to climate warming.

In this study, we employ a process-based crop model driven by the outputs of a regional climate model to evaluate the impact of climate change on maize yield in NCP. We attempt to investigate the potential impact of genotypic adaptation to heat stress, namely improved tolerance of pollen viability (grain number formation) to heat stress. The objective is to identify effective adaptation to mitigate the negative climate warming.

\section{MATERIALS AND METHODS}

\subsection{Study sites and crop data}

Three study sites (Figure 1), Yuanyang $\left(35.05^{\circ} \mathrm{N}, 113.97^{\circ} \mathrm{E}\right)$ in Henan Province, Yongnian $\left(36.78^{\circ} \mathrm{N}, 114.49^{\circ} \mathrm{E}\right)$ and Shijiazhuang $\left(38.04^{\circ} \mathrm{N}\right.$, $\left.114.52^{\circ} \mathrm{E}\right)$ in Hebei Province, were selected for this study. They are representative of the climate in the maize production region NCP. At the three sites, maize variety Xundan 29 was planted with density of 7 plants $\mathrm{m}^{-2}$ in 2008 and 2009 . Irrigation $(60 \mathrm{~mm})$ was applied after sowing and nitrogen fertilizers were applied twice, at planting $(100 \mathrm{~kg}$ $\mathrm{N} \mathrm{ha}^{-1}$ ) and jointing stage (150 $\left.\mathrm{kg} \mathrm{N} \mathrm{ha}^{-1}\right)$ in both seasons. Crop phenological stages (emergence, flowering and maturity) and final grain yield were recorded and used for model evaluation (Table 1)

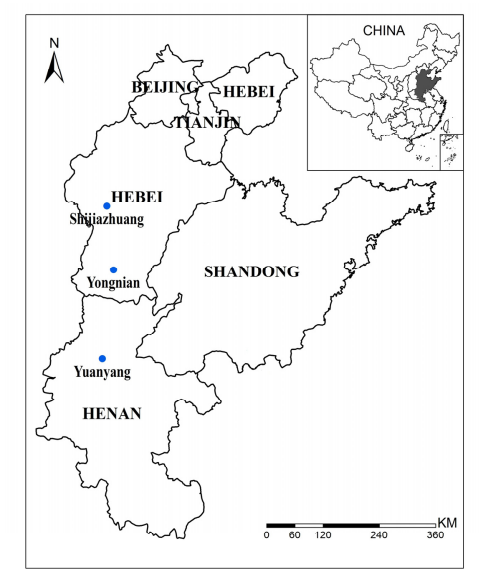

Figure 1. The study sites in the North China Plain. 
Table 1. The information of experiments

\begin{tabular}{lcclllc}
\hline Site & Experiment year & Sowing date & Emergence date & Flowering date & Maturity date & Yield $\left(\mathrm{t} \mathrm{ha}^{-1}\right)$ \\
\hline Yuanyang & 2008 & Jun.14 & Jun.20 & Aug.6 & Oct.1 & 11.9 \\
& 2009 & Jun.16 & Jun.23 & Aug.10 & Oct.1 & 9.9 \\
\multirow{2}{*}{ Yongnian } & 2008 & Jun.13 & Jun.20 & Aug.6 & Oct.1 & 12.7 \\
& 2009 & Jun.16 & Jun.24 & Aug.10 & Oct.1 & 11.4 \\
\multirow{3}{*}{ Shijiazhuang } & 2008 & Jun.13 & Jun.21 & Aug.6 & Oct.3 & 8.5 \\
& 2009 & Jun.10 & Jun.15 & Aug.5 & Sep.27 & 9.4 \\
\hline
\end{tabular}

\subsection{APSIM model, parameterization and testing}

APSIM (Keating et al., 2003) was employed to simulate the maize yield in response to different crop varieties in future climate. The cultivar parameters for maize variety Xundan 29 were derived using a trial-and-error method with the data from 2008 (Table 2). Then the model was tested against all the experimental data in 2008 and 2009. Figure 2 shows the comparison between observed and simulated yields in 2008 and 2009. The slope $(\alpha=0.95)$ of the regression line implied that the model tended to slightly underestimate maize yield towards high yield range. The coefficient of determination for $\mathrm{y}=\mathrm{x}$ line $\left[r^{2}(1: 1)\right]$ reached a value of 0.89 , indicating about $90 \%$ of the variation in measured grain yield could be explained by the model. Root mean squared error (RMSE) was $0.7 \mathrm{tha}^{-1}$, which represents less than $10 \%$ of observed values. The performance of the model was considered to be satisfactory.

\subsection{Climate data and climate change projections}

The outputs of a regional climate model RegCM4 (Giorgi et al., 2012), run under low and high emission scenarios of RCPs 4.5 and 8.5, were used in the present study. The time slices of 1980-2005 and 2020-2045 were selected from outputs of RegCM4 to represent the baseline and future climate, respectively. Compared with the baseline climate conditions, the monthly mean maximum temperature increased by $0.6^{\circ} \mathrm{C}$ to $0.9^{\circ} \mathrm{C}$ under $\mathrm{RCP} 4.5$ and by $1.4^{\circ} \mathrm{C}$ to $1.6^{\circ} \mathrm{C}$ under RCP 8.5 at all sites during the maizegrowing season (Jun-Sep). The increases of mean minimum temperature in the future scenarios were greater than those of the mean maximum temperature for all the sites, which ranged from $0.9^{\circ} \mathrm{C}$ to $1.2^{\circ} \mathrm{C}$ under RCP4.5 and from $1.5^{\circ} \mathrm{C}$ to $1.7^{\circ} \mathrm{C}$ under RCP 8.5 , respectively (Table 3 ).

Table 2. Maize parameters of cultivar Xundan 29 in the study sites

\begin{tabular}{ll}
\hline \multicolumn{1}{c}{ Parameters } & Value \\
\hline Thermal time required from emergence to end of juvenile $\left({ }^{\circ} \mathrm{C} \mathrm{d}\right)$ & 130 \\
Thermal time required from flowering to maturity $\left({ }^{\circ} \mathrm{C} \mathrm{d}\right)$ & 850 \\
Photoperiod slope $\left({ }^{\circ} \mathrm{C} \mathrm{h}^{-1}\right)$ & 18 \\
Potential grain numbers per head & 600 \\
Grain-filling rate $(\mathrm{mg}$ of grain per day) & 11 \\
Maximum temperature above which grain number is reduced $\left({ }^{\circ} \mathrm{C}\right)$ & 38 \\
\hline
\end{tabular}

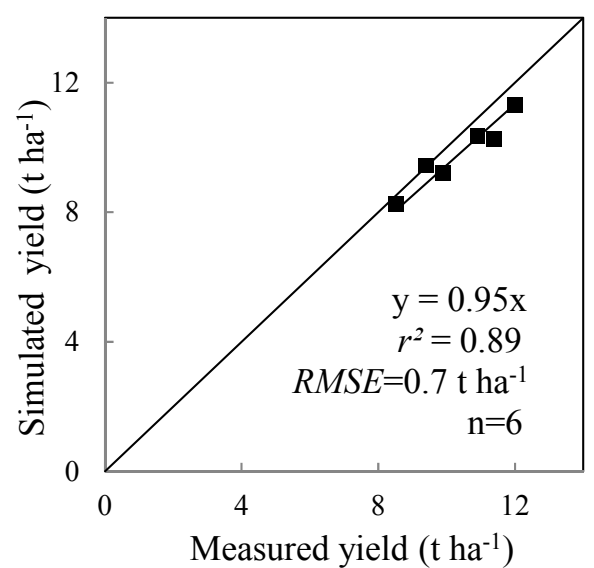

Figure 2. Comparison between measured and simulated maize yields for three sites. 
Table 3. The increase $(\Delta \mathrm{T})$ in monthly mean maximum $\left(\mathrm{T}_{\max }\right)$ and minimum $\left(\mathrm{T}_{\min }\right)$ temperature in $2020-2045$ reference to the baseline $(\mathrm{T})$ in 1981-2005

\begin{tabular}{|c|c|c|c|c|c|c|c|c|c|}
\hline \multirow{2}{*}{ Site } & \multirow{2}{*}{ Climate project } & \multicolumn{4}{|c|}{$\mathrm{T}_{\max }\left({ }^{\circ} \mathrm{C}\right)$} & \multicolumn{4}{|c|}{$\mathrm{T}_{\min }\left({ }^{\circ} \mathrm{C}\right)$} \\
\hline & & Jun & Jul & Aug & Sep & Jun & Jul & Aug & Sep \\
\hline \multirow[t]{3}{*}{ Yuanyang } & Baseline (T) & 35.3 & 34.9 & 34.0 & 28.5 & 20.8 & 22.6 & 21.7 & 15.9 \\
\hline & $\mathrm{RCP} 4.5(\Delta \mathrm{T})$ & 0.5 & 0.9 & 0.7 & 1.6 & 1.1 & 1.2 & 1.0 & 1.6 \\
\hline & $\mathrm{RCP} 8.5(\Delta \mathrm{T})$ & 1.2 & 1.2 & 1.3 & 2.2 & 1.1 & 1.2 & 1.5 & 2.3 \\
\hline \multirow[t]{3}{*}{ Yongnian } & Baseline (T) & 34.8 & 34.5 & 33.4 & 27.4 & 20.2 & 22.0 & 20.9 & 14.9 \\
\hline & $\mathrm{RCP} 4.5(\Delta \mathrm{T})$ & 0.3 & 0.9 & 0.2 & 1.0 & 0.7 & 1.2 & 0.7 & 1.4 \\
\hline & $\mathrm{RCP} 8.5(\Delta \mathrm{T})$ & 0.7 & 1.7 & 1.1 & 1.9 & 0.9 & 1.4 & 1.5 & 2.2 \\
\hline \multirow[t]{3}{*}{ Shijiazhuang } & Baseline (T) & 34.0 & 34.1 & 32.4 & 26.3 & 19.0 & 21.2 & 19.8 & 13.6 \\
\hline & $\mathrm{RCP} 4.5(\Delta \mathrm{T})$ & 0.5 & 0.6 & 0.4 & 1.0 & 0.7 & 0.9 & 0.7 & 1.4 \\
\hline & $\mathrm{RCP} 8.5(\Delta \mathrm{T})$ & 0.6 & 2.1 & 1.7 & 2.0 & 1.1 & 1.6 & 1.9 & 2.3 \\
\hline
\end{tabular}

\subsection{Assumptions of increased heat tolerance of pollen viability}

Carberry et al. (1989) indicated that high maximum temperatures above $38^{\circ} \mathrm{C}$ around anthesis could reduce grain-numbers per ear of maize based on analysis of the data from Herrero and Johnson (1980) and Schoper et al. (1986). Based on this finding, a high-temperature stress function was incorporated in the APSIM-Maize model to simulate grain-number reduction when the maximum temperatures exceeded $38^{\circ} \mathrm{C}$ during the critical period from flag leaf to start of grain filling stage. We assumed a 'new' maize variety that is similar to Xundan29, but has a higher tolerance of pollen viability or grain number development to maximum temperature to a threshold value of $40^{\circ} \mathrm{C}$ as compared to $38^{\circ} \mathrm{C}$ Xundan 29 (Table 2).

\subsection{Simulations and analysis}

To investigate the possible impacts of climate change on maize yield, simulation was carried out using variety Xundan29 sown on the current common planting date that employed by agro-meteorological station of the Chinese Meteorological Administration near the study sites from 1981 to 2010. The simulation was conducted assuming no water, nutrient and other stresses.

The adaptation strategy of using 'new' maize variety with increased tolerance of grain number formation to high temperature was tested to cope with the negative climate change impacts. The relative changes in yield and grains number under the scenarios, referred to yield and grain number predicted for the baseline, were used in the analysis rather than absolute values.

\section{RESULTS AND DISCUSSION}

\subsection{Maize yield under climate change}

The predicted changes in overall production for each site under RCP4.5 and RCP8.5 are provided in Table 4 and Figure 3. On average, more reduction in maize yield was simulated from northern to southern sites, varying from $5 \%$ to $19 \%$ and from $7 \%$ to $19 \%$ under RCP4.5 and RCP8.5, respectively. The overall change in mean maize yield showed a reduction of $12 \%$ relative to $1980-2005$. This is in line with previously studies which show a reduction in maize yield between $13 \%$ and $29 \%$ during 2050s in NCP (Guo et al., 2010; Tao and Zhang, 2010). Large decreases in maize yield by $75 \%$ were simulated at all three sites (Figure 3), indicating yield loss in extreme years under RCP4.5. 
Table 4. Mean percent change (\%) in yield and in grain number for maize grain development without and with new variety during 2020-2045, relative to 1980-2005.

\begin{tabular}{|c|c|c|c|c|c|}
\hline \multirow{2}{*}{ Site } & \multirow{2}{*}{ Climate projection } & \multicolumn{2}{|c|}{ Grain number (\%) } & \multicolumn{2}{|c|}{ Yield change $(\%)$} \\
\hline & & Local variety & New variety & Local variety & New variety \\
\hline \multirow[t]{2}{*}{ Yuanyang } & RCP4.5 & -21 & +3 & -19 & 1 \\
\hline & $\mathrm{RCP} 8.5$ & -19 & +2 & -19 & 1 \\
\hline \multirow[t]{2}{*}{ Yongnian } & $\mathrm{RCP} 4.5$ & -3 & +11 & -6 & 5 \\
\hline & $\mathrm{RCP} 8.5$ & -8 & +13 & -15 & 7 \\
\hline \multirow[t]{2}{*}{ Shijiazhuang } & $\mathrm{RCP} 4.5$ & -3 & +11 & -5 & 5 \\
\hline & RCP8.5 & -4 & +18 & -7 & 9 \\
\hline
\end{tabular}

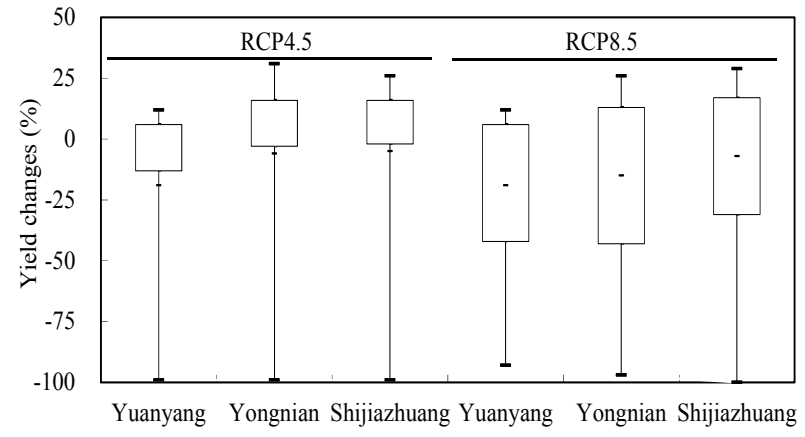

Figure 3. Percent change in maize yield of local variety during 2020-2045. The box plots show the 5, 25, 75 and 95 percentiles. The dots represent the mean value of the data.

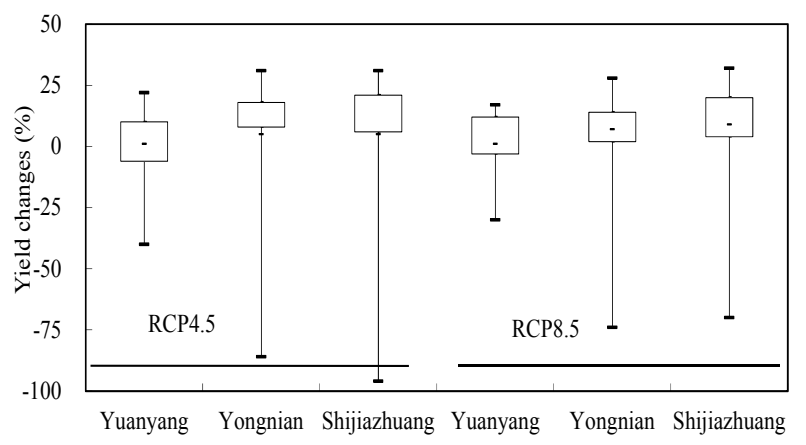

Figure 4. Percent change in maize yield of a 'new' variety during 2020-2045. The box plots show the 5, 25, 75 and 95 percentiles. The dots represent the mean value of the data.

\subsection{Adaptation: increased tolerance of grain number to temperature}

Results of using 'new' variety with increased tolerance of grain number formation to high temperature as adaptation are given in Table 4 and Figure 4. Under future scenarios, temperature during grain development period was predicted to be higher. Without the use of the 'new' variety with higher temperature tolerance as a substitute, large reductions in maize yield were predicted due to decreasing grain number as a result of heat stress. The decrease in grain number in future scenarios ranged from $3 \%$ to $21 \%$, with the largest decrease occurring at Yuanyang (Table 4). With the adaptation of the 'new' variety with increased heat tolerance, the negative effects of warmer climate condition on yield loss could be offset. The grain number during grain development would increase by an average of $10 \%$ (range $2 \%$ and $18 \%$ depending on sites and climate scenarios). The mean yield with 'new' variety was simulated to increase by $7 \%$ and $6 \%$ on average in Shijiazhuang and Yongnian in future scenarios, and to remain at the current level in Yuanyang..

Our simulation results revealed that future warming climate will like reduce maize yield by its adverse effect on grain number formation in North China Plain, as grain number of maize is sensitive to high temperature during grain development (Barnabás et al., 2008; Edreira et al., 2011). Introduction of new varieties with increased tolerance of grain number formation to high temperature would be an efficient way to adapt to the increased heat stress during grain filling period in future climates. In other similar investigations, Gouache et al. (2012) indicated that using wheat variety with increased threshold temperature of heat stress during grain filling from $25^{\circ} \mathrm{C}$ to $26^{\circ} \mathrm{C}$ could be the effective adaptation strategy in France. Likewise, Krishnan et al. (2007) showed that using rice variety with increased tolerance of spikelet fertility to maximum temperature to a threshold value of $38.5^{\circ} \mathrm{C}$ as compared to $36.5^{\circ} \mathrm{C}$ could offset the negative impact of climate warming in India. This indicates that new varieties with increase heat tolerance of grain number formation needs to be considered in order to mitigate the negative impact of extreme high temperatures. 


\section{CONCLUSION}

While previous studies showed that varietal change to late maturing cultivars could stabilize the maize yield under rising temperature in the North China Plain, our results demonstrate that using variety with increased tolerance of grain number formation to higher temperatures could be an effective adaptation strategy in reducing the adverse climate change impact on maize yield. The yield of the 'new' variety was simulated to increase by $1 \%$ to $9 \%$ in $2020-2045$ as compared to the current maize varieties.

\section{ACKNOWLEDGMENT}

This work was supported by the Special Research Fund for Meteorology of China (Grant No. GYHY201406026). We gratefully acknowledge Prof. Xuejie Gao from Institute of Atmospheric Physics, Chinese Academy of Sciences for providing the climate projections data.

\section{REFERENCES}

Andrade, F. H., Vega, C., Uhart, S., Cirilo, A., Cantarero, M., and Valentinuz, O. (1999). Kernel number determination in maize. Crop Science, 39, 453-459.

Barnabás B, Jäger K, Fehér A. 2008. The effect of drought and heat stress on reproductive processes in cereals. Plant, Cell and Environment, 31, 11-38.

Carberry, P. S., Muchow, R. C., and McCown, R. L. (1989). Testing the CERES-Maize simulation model in a semi-arid tropical environment. Field Crops Research, 20, 297-315.

Cárcova, J., and Otegui, M. E. (2001). Ear temperature and pollination timing effects on maize kernel set. Crop Science, 41, 1809-1815.

Deryng, D., Conway, D., Ramankutty, N., Price, J., and Warren, R. (2014). Global crop yield response to extreme heat stress under multiple climate change futures. Environmental Research Letters, 9, 034011.

Edreira, J. I. R., Carpici, E. B., Sammarro, D., and Otegui, M. E. (2011). Heat stress effects around flowering on kernel set of temperate and tropical maize hybrids. Field Crops Research, 123, 62-73.

Giorgi, F., Coppola, E., and Solmon, F. (2012). RegCM4: Model description and illustrative basic performance over selected CORDEX domains. Climate Research, 52, 7-29.

Gouache, D., Bris, X. L., Bogard, M., Deudon, O., Pagé, C., and Gate, P. (2012). Evaluating agronomic adaptation options to increasing heat stress under climate change during wheat grain filling in France. European Journal of Agronomy, 39, 62-70.

Guo, R. P., Lin, Z. H., Mo, X. G., and Yang, C. L. (2010). Responses of crop yield and water use efficiency to climate change in the North China Plain. Agricultural Water Management, 97, 1185-1194.

Herrero, M. P. and Johnson, R. R. (1980). High-temperature stress and pollen viability of maize. Crop Science, 20, 796-800.

Keating, B. A., et al. (2003). An overview of APSIM, a model designed for farming systems simulation. European Journal of Agronomy, 18, 267-288.

Krishnan, P., Swain, D. K., Chandra Bhaskar, B., Nayak, S. K, and Dash, R. N. (2007). Impact of elevated $\mathrm{CO}_{2}$ and temperature on rice yield and methods of adaptation as evaluated by crop simulation studies. Agriculture, Ecosystems and Environment, 122, 233-242.

Liu, Z., Hubbard, K. G., Lin, X., and Yang, X. (2013). Negative effects of climate warming on maize yield are reversed by the changing of sowing date and cultivar selection in Northeast China. Global Change Biology, 19, 3481-3492.

Lobell, D. B., Hammer, G. L., McLean, G., Messina, C., Roberts, M. J., and Schlenker, W. (2013).The critical role of extreme heat for maize production in the United States. Nature Climate Change, 3, 497501.

Luo, Q., Bellotti, W., Williams, M., and Wang, E. (2009). Adaptation to climate change of wheat growing in South Australia: analysis of management and breeding strategies. Agriculture, Ecosystems and Environment, 129, 261-267.

Prasad, P. V. V., Boote, K. J., and Allen, J. L. H. (2006). Adverse high temperature effects on pollen viability, seed-set, seed yield and harvest index of grain-sorghum [Sorghum bicolor (L.) Moench] are more severe at elevated carbon dioxide due to higher tissue temperatures. Agricultural and Forest Meteorology, 139, 237251.

Rezaei, E. E., Webber, H., Gaiser, T., Naab, J., and Ewert, F. (2014). Heat stress in cereals: Mechanisms and modelling. European Journal of Agronomy, doi.org/10.1016/j.eja.2014.10.003.

Schoper, J. B., Lambert, R. J. and Vasilas, B. L., (1986). Maize pollen viability and ear receptivity under water and high temperature stress. Crop science, 26, 1029-1033. 
Tachie-Obeng, E., Akponikpe, P. B. I., and Adiku, S. (2013). Considering effective adaptation options to impacts of climate change for maize production in Ghana. Environmental Development, 5, 131-145.

Tao, F., and Zhang, Z. (2010). Adaptation of maize production to climate change in North China Plain: Quantify the relative contributions of adaptation options. European Journal of Agronomy, 33, 103-116.

Tao, F., Zhang, Z., Shi, W., Liu, Y., Xiao, D., Zhang, S., Zhu, Z., Wang, M., and Liu, F. (2013). Single rice growth period was prolonged by cultivars shifts but yield was damaged by climate change during 19812009 in China, and late rice was just opposite. Global Change Biology, 19, 3200-3209.

Teixeira, E. I., Fischer, G., van Velthuizen, H., Walter, C., and Ewert, F. (2013). Global hot-spots of heat stress on agricultural crops due to climate change. Agricultural and Forest Meteorology, 170, 206-215.

Tollenaar, M., Dwyer, L. M., Stewart, D. W., and Ma, B. L. (2000). Physiological parameters associated with differences in kernel set among maize hybrids. In: Physiology and Modeling Kernel Set in Maize. 115-130.

Yu, Q., Li, L., Luo, Q., Eamus, D., Xu, S., Chen, C., Wang, E., Liu, J., and Nielsen, D. C. (2014). Year patterns of climate impact on wheat yields. International Journal of Climatology, 34, 518-528.

Zhang, Y., Feng, L. P., Wang, J., Wang, E. L., and Xu, Y. L. (2013).Using APSIM to explore wheat yield response to climate change in the North China Plain: the predicted adaptation of wheat cultivar types to vernalization. Journal of Agricultural Science, Cambridge, 151, 836-848.

Zhao, L., Li, C., Liu, T., Wang, X., Seng, S., and Pan, X., (2012). Genotypic Responses and Physiological Mechanisms of Maize (Zea mays L.) to High Temperature Stress during Flowering. Acta Agronomica Sinica, 38, 857-864.(in Chinese) 